\title{
Desenvolvimento regional e desigualdade socioespacial fluminense nos anos 2010
}

Helcio de Medeiros Junior *

\begin{abstract}
Resumo
O ciclo de investimentos no Estado do Rio de Janeiro desde fins do século passado levou a que as regiões receptoras das inversões apresentassem maior crescimento da renda per capita e alcançassem maior desenvolvimento, causando, entre 2000 e 2010, maior disparidade de renda entre as regiões. As regiões que apresentaram maior desenvolvimento tiveram, em sua maioria, como principal componente uma maior produtividade do trabalho, processo oposto das que apresentaram estagnação do crescimento da renda per capita. Mantida a orientação dos investimentos, os anos 2010 assistirão à exacerbação do desequilíbrio da renda regional, com agravamento da desigualdade socioespacial, de acordo com o que Myrdal (1972) defendia, e não como Williamson (1977) sugeria.
\end{abstract}

Palavras-chave: Desenvolvimento regional; Renda per capita; Estado do Rio de Janeiro; Desigualdade socioespacial.

\begin{abstract}
The investment cycle in the State of Rio de Janeiro since the end of the last century led to the receptor regions of the inversions presented greater growth in income per capita and achieved greater development, causing between 2000 and 2010, greater income disparity between regions. The regions that showed greater development had, in most cases, as the main component greater labor productivity, the opposite of those with stagnant growth in per capita income process. Maintained the orientation of investments, the years 2010 to attend exacerbating the imbalance of regional income, with worsening socio inequality, according to what Myrdal (1972) argued, not as Williamson (1977) suggested.
\end{abstract}

Keywords: Regional development; Income per capita; State of Rio de Janeiro; Socio-spatial inequality. 


\section{Introdução}

Desde o século passado o Estado do Rio de Janeiro tem passado por mudanças que alteraram sua participação na economia nacional (Silva, 2004) e reconfiguraram o território fluminense, sem, no entanto, gerar centros regionais estruturados que reduzissem a vinculação com o núcleo metropolitano (Oliveira, 2008). Apesar das mudanças terem proporcionado maior modernização do parque produtivo e crescimento de atividades específicas, a evolução da economia fluminense passou a ser inferior à observada no nível nacional, levando à perda da participação relativa (Silva, 2012) existente no início do século XX. Em termos regionais, as mudanças não foram capazes de abalar a hegemonia da Região Metropolitana, que manteve em seu espaço parte relevante da estrutura industrial e o maior peso no terciário fluminense, conservando, assim, a chamada "macrocefalia metropolitana" (Natal, 2005; Silva, 2012), haja vista concentrar em 2010 cerca de 74\% da população fluminense, gerar 65\% do valor adicionado bruto e deter 77\% dos postos de trabalho das regiões (Medeiros Junior, 2013a).

A partir das décadas de 1980 e 1990, as regiões do Norte Fluminense, em razão da atividade de extração de petróleo e gás, e do Médio Paraíba, devido às indústrias metalmecânica e automobilística, passaram a apresentar forte atratividade, o que elevou suas taxas de crescimento populacional, fato que também se observou na região das Baixadas Litorâneas, limítrofe ao sul à do Norte Fluminense, bem como na região da Costa Verde, que possui unidade da indústria naval, terminal de minérios e a usina de Angra dos Reis. Essas regiões, em sua maioria receptoras de investimentos industriais, tornaram-se alternativa ao núcleo metropolitano e passaram a apresentar indicações de aumento da atividade econômica e da produtividade regional (Medeiros Junior, 2013c, 2013d). O ganho populacional e de atividade econômica nessas regiões, bem como a ausência de sinais de mesma natureza naquelas que não foram mencionadas, sugere ser indicação do desequilíbrio espacial dos benefícios que o desenvolvimento econômico em curso no território fluminense tem proporcionado.

Assim, este trabalho se propõe observar como se deu o desenvolvimento econômico regional no primeiro decênio do presente século, desagregando-o em seus componentes para avaliar se as regiões que têm recebido investimentos seriam aquelas que apresentaram resultados mais expressivos, bem como ponderar pela desigualdade socioespacial decorrente. Para alcançar os objetivos a que se propõe, o presente texto se estrutura em três sessões, contemplando além desta Introdução: a primeira, na qual se farão considerações sobre o indicador utilizado para a avaliação do desenvolvimento econômico e sua decomposição; na segunda observar-se-ão, a partir dos resultados obtidos, as fontes e os níveis de desenvolvimento vis-à-vis a desigualdade regional e o desenvolvimento social, e, na terceira e última sessão, de caráter conclusivo, far-se-ão reflexões sobre as impressões obtidas do confronto dos indicadores utilizados, bem como do que se espera para a evolução do desenvolvimento em curso nesta década.

\section{1 - Desenvolvimento econômico regional}

Por ser controverso e, portanto, de difícil aproximação ao consenso, desenvolvimento econômico tem sido tratado em termos conceituais e de forma bastante simplificada segundo, basicamente, dois olhares: o dos de economistas de orientação neoclássica e os de orientação crítica. Os primeiros costumam considerar crescimento econômico como sinônimo de 
desenvolvimento econômico e veem a distribuição da renda obtida entre os proprietários do fatores de produção como melhoria dos padrões de vida, mas as evidências mostram que os frutos da expansão não beneficiam necessariamente a economia e a população como um todo. No capitalismo, os detentores do capital buscam acumulação e não têm em perspectiva distribuir o que obtêm, motivo por que as desigualdades (renda pessoal e regional, por exemplo) são produzidas no seio do próprio sistema capitalista. Já os de orientação crítica, ou estruturalista, consideram o desenvolvimento como expressão de mudanças estruturais econômicas, sociais, políticas, institucionais, dos níveis de produtividade e da renda média da população, e não meramente pela existência de crescimento econômico. Assim, segundo Souza (2007), a corrente estruturalista entende o desenvolvimento econômico como resultado da:

[...] existência de crescimento econômico contínuo (g), em ritmo superior ao crescimento demográfico $\left(\mathrm{g}^{*}\right)$, envolvendo mudanças de estruturas e melhoria de indicadores econômicos, sociais e ambientais. Ele compreende um fenômeno de longo prazo, implicando o fortalecimento da economia nacional, a ampliação da economia de mercado, a elevação geral da produtividade e do nível de bem-estar do conjunto da população, com a preservação do meio ambiente. [...] (Souza, 2007:7)

Essa percepção do desenvolvimento econômico será adotada neste trabalho, por ser considerada mais abrangente e adequada à atual configuração do sistema estatístico nacional, já que em termos regionais não há condições de avaliar diretamente o crescimento regional em espaços geográficos inferiores ao dos Estados, haja vista que o indicador adequado para esta aferição, o "índice de volume do valor adicionado bruto", não é apurado no nível dos municípios. Portanto, mesmo que se desejasse, não seria possível confrontar crescimento e desenvolvimento em espaços menores do que o das unidades da Federação, uma vez que as regiões de interesse são agregações de municípios dentro do Estado do Rio de Janeiro.

Em vista de suas características, considera-se que o desenvolvimento econômico a avaliar neste trabalho é por natureza desigual, fruto da evolução do sistema capitalista, como se verá a seguir.

\subsection{Desenvolvimento desigual e combinado e desigualdade inter-regional}

A diferenciação espacial promovida pelo capital leva a que cidades e regiões tenham níveis e dinâmicas de crescimento e desenvolvimento desiguais, tendo em vista que nos territórios eleitos para sua expansão ocorre a homogeneização mediante a padronização de processos, enquanto naqueles que não são alcançados por atividades econômicas que habitem a fronteira de expansão do capitalismo se estabeleça um relativo "atraso", o que resulta em heterogeneidade espacial. Enquanto nos territórios "adiantados" há concentração do capital e convergência de processos, nos demais se manifesta dispersão do capital e divergência de processos.

Segundo Trotsky (1977), a diferenciação não impõe às áreas atrasadas um eterno subdesenvolvimento, nem obriga às mesmas passarem pelas etapas históricas das desenvolvidas para tornarem-se adiantadas. As regiões atrasadas combinariam inovações tecnológicas, políticas e culturais produzidas nos países avançados com relações sociais por vezes pré-capitalistas existentes em seu ambiente. A esta proposição denominou-se "Lei do desenvolvimento desigual e combinado", que caracteriza a trama existente entre territórios desnivelados no plano internacional, nacional e regional, com variados níveis de desenvolvimento. 
O desnível regional, por sua vez, não tornaria inviável o desenvolvimento do capitalismo, mas o favoreceria. Numa relação de dominação e dependência, as regiões adiantadas consumiriam elementos disponíveis em espaços menos desenvolvidos, favorecendo maior acumulação de capital e aumento da taxa de lucro. Nesse aspecto, Neil Smith (1988) vê interseção entre as tradições geográfica e política ao sugerir que "uma teoria do desenvolvimento desigual oferece a chave-mestra para determinar o que caracteriza a geografia específica do capitalismo" (Smith, 1988:16-17). Sua lógica deriva de tendências opostas (diferenciação e igualização) e resulta da necessidade de imobilização contínua e desigual do capital fixo, e é nas aglomerações urbanas que encontra receptividade para maximizar lucros e impor sua lógica.

A evolução das desigualdades regionais derivada do desenvolvimento desigual, no entanto, é motivo de controvérsia. Para os neoclássicos, os desequilíbrios regionais desaparecerão por causa do funcionamento do mercado, haja vista que a remuneração dos fatores de produção se igualaria como resultado da mobilidade inter-regional. Segundo a teoria neoclássica do crescimento econômico, a tendência de queda no tempo das diferenças dos valores relativos da renda per capita promoveria sua convergência (Resende e Magalhães, 2013). Para Myrdal (1972) e Williamson (1977), no entanto, isso não é assim tão simples. Myrdal acreditava que as desigualdades iniciais se alargariam indefinidamente porque os fluxos de fatores de produção tenderiam a orientarem-se e concentrarem-se nas áreas alcançadas pelo desenvolvimento, favorecendo maior crescimento no momento seguinte. Já Williamson concordava com Myrdal apenas quanto aos momentos iniciais, mas considerava que, atingido um limite, a disparidade regional tenderia a se reduzir: (a) por conta do estancamento da migração de mão de obra para a região rica; (b) devido à exaustão das economias externas na região rica; (c) pelo desenvolvimento do mercado de capitais na região pobre; e (d) por programas redistributivos implementados pelo governo central em benefício da região pobre.

Entre o extremo da hipótese da convergência de renda dos neoclássicos e da desigualdade crescente de Myrdal, Williamson propôs algo mais próximo do que se observa na trajetória das nações, mas entre os fatores que considerou determinantes para a reversão do processo, (c) e (d) dificilmente se aplicariam no nível regional, haja vista a inexistência de mercado de capitais em cidades fora do núcleo metropolitano, e a precariedade do governo estadual (central) em contar com recursos orçamentários e motivação política que compensem a condição das regiões deprimidas. Neste particular, Myrdal concordava com Williamson, pois via no Estado um agente indutor de políticas igualitárias que promoveriam o fortalecimento de efeitos propulsores, ao mesmo tempo em que combateriam os efeitos regressivos, levando a que as desigualdades se reduzissem. No entanto, provavelmente por força de injunções políticas, os recursos públicos que permitiriam ações combinadas nesta direção serão destinados às regiões ricas.

\subsection{Indicador de desenvolvimento econômico}

A complexidade proposta pela perspectiva crítica (ou estruturalista) do desenvolvimento econômico sugeriria a adoção de uma cesta de indicadores que cobrissem as dimensões consideradas em sua definição. Este tem sido o caminho adotado por agências internacionais quando se propõem a fazer levantamentos mais exaustivos, contemplando indicadores que abordem várias das nuances mencionadas na definição que adotamos para nortear este trabalho. Entretanto, não há indicador sintético que abranja todas as dimensões. 
Dentre os indicadores normalmente contemplados em estudos desta natureza, há o Produto Interno Bruto per capita (PIB ou renda per capita), que será adotado nesta investigação. Este indicador procura sintetizar o nível de bem-estar da população, já que representa em média a renda gerada num determinado espaço geográfico pelos residentes. Por expressar uma média, e tendo em vista que há diferenciais de renda que o desqualificariam como única dimensão a ser considerada (caso de economias em desenvolvimento), sugere-se confrontálo a um outro indicador que considere a desigualdade de renda. Para os fins desse esforço, utilizar-se-á o índice de Gini, que mede a desigualdade da renda domiciliar per capita, para avaliar se a renda observada é mais ou menos concentrada.

Além disso, a escolha do PIB per capita foi feita com o propósito de avaliar os elementos em que pode ser decomposto, permitindo um olhar alternativo. Por definição, o PIB (ou renda) per capita é a multiplicação do produto por trabalhador pela participação da população no processo produtivo, como segue:

$$
\frac{P I B}{\text { Pop }}=\left(\frac{P I B}{\text { Emprego }}\right)\left(\frac{\text { Emprego }}{\text { Pop }}\right)
$$

onde: $\mathrm{PIB}=$ Produto interno bruto a preço de mercado; Pop = população residente; e Emprego = número de pessoas ocupadas, abrangendo todas as categorias de ocupação levantadas no Censo Demográfico para os anos de 2000 e 2010. A categoria emprego, neste caso, difere da empregada por Ferreira e Veloso (2013), que optaram por utilizar a força de trabalho (PEA). Esta, além dos ocupados, agrega os desocupados, ou os trabalhadores que no momento do levantamento não tinham uma ocupação, apesar de terem tentado participar do mercado de trabalho.

A opção neste trabalho pelos ocupados prende-se ao fato de que a decomposição permite olhares alternativos, e que serão úteis para a análise do comportamento regional da renda per capita. Enquanto o primeiro termo da equação reflete uma dimensão mais econômica, por depender, muito resumidamente, das características do processo produtivo posto em marcha pelas empresas e das especificidades inerentes à força de trabalho utilizada na produção, o segundo expressaria aspectos sociais. Sanchez (1994) denomina a razão do segundo termo como "taxa de ocupação da população total”, que permite avaliar a participação da população na atividade econômica.

A decomposição também é útil por discriminar dois efeitos que podem determinar o comportamento da renda per capita. O primeiro termo representa o produto por trabalhador, proxy da produtividade do trabalho, e o segundo representa a utilidade do trabalho, ou a fração da população residente que contribui para o processo produtivo. De outra forma, se a decomposição tomar como referência as razões em termos de taxas de variação, sua soma representa a taxa de variação do PIB (ou renda) per capita. Assim, o PIB per capita pode se elevar (ou reduzir-se) se: a) ceteris paribus, os trabalhadores tornaram-se mais produtivos (improdutivos); b) ceteris paribus, a participação do trabalho na população cresceu (caiu); ou c) ambos caminharam na mesma direção e se elevaram, ou em direção oposta, sendo que o crescimento (decrescimento) de um dos componentes compensaria o do outro.

Em termos operacionais, e tendo em vista que o segundo termo é composto por variáveis reais, optou-se por ajustar a variação nominal do PIB per capita ao efeito da variação dos 
preços para que se obtivesse a variação real. ${ }^{1}$ Para tanto, utilizou-se o índice do preço do valor adicionado a preço básico do total das atividades econômicas, disponibilizado pela Fundação CEPERJ (2014).

\section{2 - Desenvolvimento econômico regional fluminense e desigualdade socioespacial}

O Estado do Rio de Janeiro recebeu investimentos ao longo da primeira década do presente século de cerca de R\$ 100 bilhões (FUNDAÇÃO CEPERJ, 2012) e, de acordo com pesquisas recentes, o volume das inversões só tem aumentado. Segundo levantamentos realizados pela Federação das Indústrias do Estado do Rio de Janeiro (FIRJAN, 2009, 2012, 2014), as inversões programadas para o período 2014-2016 alcançam cerca de R $\$ 235,6$ bilhões para a instalação de refinarias de petróleo, construção de navios petroleiros, de automóveis e de complexo portuário no interior do estado, e que abrangem os segmentos de construção naval, transporte/logística, petroquímico, energia, borracha e desenvolvimento urbano.

Em termos setoriais, e de acordo com a nomenclatura adotada, o setor predominante na recepção dos investimentos nas três edições que cobrem biênios consecutivos desde 2010 é o de petróleo e gás, responsável por mais da metade do volume estimado (Tabela 1). Em termos regionais, os investimentos localizáveis em uma só região do Estado demonstraram que as regiões privilegiadas são: Metropolitana (desenvolvimento urbano, saneamento básico, habitação, hospedagem, bebidas, farmacêutica, petroquímica, siderurgia, construção naval, transporte/logística); do Médio Paraíba (borracha, metalurgia, siderurgia e automobilístico); Norte Fluminense (siderurgia, construção naval, energia e transporte/logística); da Costa Verde (energia); Serrana (minerais não-metálicos, plástico, metalurgia, energia e transporte/ logística) e Noroeste Fluminense (minerais não-metálicos, desenvolvimento urbano, alimentos e energia).

Pelo que se observa, grande parte dos investimentos tem se baseado no setor secundário, cabendo à infraestrutura cerca de um quinto do total, na média dos levantamentos. Keynes (1988) e Kalecki (1985) viam o investimento como o motor do sistema econômico, uma vez que seus efeitos elevam os níveis de atividade e emprego e alimentam maior demanda por bens e serviços, num círculo virtuoso que eleva a acumulação de capital e os lucros dos capitalistas. Adaptadas à escala regional, as contribuições de Keynes e Kalecki indicam que os sistemas econômicos locais receptores dos investimentos assistirão a transformações estruturais que se estenderão aos territórios que conformam seu entorno imediato, e a mudança decorrente será de natureza multidimensional (social, econômica, ambiental, política etc.).

\footnotetext{
1 Tenha-se em mente que o ajuste é uma aproximação, ou estimativa, que procura homogeneizar comportamentos heterogêneos e desconhecidos, na medida em que este trabalho se propõe a tratar de realidades econômicas regionais distintas. De antemão sabe-se que 0 sistema estatístico nacional não oferece índices de preço que permitam aproximar variáveis monetárias a condições reais em aglomerações regionais diferentes de regiões metropolitanas. Com isso, o ajuste para todos os espaços considerados mediante o uso de um único indicador, que certamente evolui de maneira diferenciada em regiões dinâmicas ou estagnadas, é a melhor aproximação à realidade.
} 
Tabela 1

Investimentos por setor de atividade no Estado do Rio de Janeiro - 2010-2016

\begin{tabular}{|c|c|c|c|c|c|c|}
\hline \multirow{2}{*}{ Setor } & \multicolumn{2}{|c|}{$2010-2012$} & \multicolumn{2}{|c|}{ 2012-2014 } & \multicolumn{2}{|c|}{ 2014-2016 } \\
\hline & (R\$ bilhões) & $\%$ & (R\$ bilhões) & $\%$ & (R\$ bilhões) & $\%$ \\
\hline Total & 126,3 & 100,0 & 211,5 & 100,0 & 235,6 & 100,0 \\
\hline Petrobrás/Petróleo e gás & 77,1 & 61,1 & 107,7 & 50,9 & 143,0 & 60,7 \\
\hline Infraestrutura & 28,6 & 22,6 & 51,0 & 24,1 & 37,9 & 16,1 \\
\hline Indústria de transformação & 20,3 & 16,0 & 40,5 & 19,2 & 40,5 & 17,2 \\
\hline Petroquímica & 15,2 & 12,0 & 6,1 & 2,9 & 20,9 & 8,9 \\
\hline Automotivo & - & - & 6,1 & 2,9 & 3,9 & 1,7 \\
\hline Indústria/Construção naval & 3,7 & 2,9 & 15,4 & 7,3 & 12,1 & 5,1 \\
\hline Siderurgia & 0,8 & 0,6 & 10,1 & 4,8 & 1,3 & 0,6 \\
\hline Farmacêutico & - & - & - & - & 1,6 & 0,7 \\
\hline Outros & 0,6 & 0,5 & 2,8 & 1,3 & 0,7 & 0,3 \\
\hline Turismo & - & - & 1,8 & 0,8 & 3,5 & 1,5 \\
\hline Instalações olímpicas & - & - & 8,6 & 4,1 & 9,9 & 4,2 \\
\hline Outros & 0,3 & 0,3 & 1,9 & 0,9 & 0,8 & 0,3 \\
\hline
\end{tabular}

Fonte: FIRJAN, Decisão-Rio.

Os investimentos regionais, no entanto, em sua grande maioria não surgem devido a um processo endógeno pregresso, mas em razão de escolhas locacionais do capital com vistas à acumulação e, dessa forma, se aproximam de um enclave (Piquet, 1993). Mediante combinação de camadas de investimento em atividades específicas, o capital estabelece bases econômicas e organização social que permitam seu desenvolvimento, e as intervenções se subordinam às realizadas em outras regiões, articulando-se a áreas geográficas distintas em relações de subordinação e num sistema de interdependências (Massey, 1995). Estas formas de subordinação, segundo Smith (1988), expressam a relação entre espaço absoluto e relativo, ou seja, que o capital ao localizar-se produz "ilhas de espaço absoluto num mar de espaço relativo" (Smith, 1988:135), e este espaço absoluto é meramente um receptáculo de recursos, que oferece condições que levam à motivação do investimento, e cujo montante e momento apropriado para implementação são decididos numa escala política e geográfica diferente, num processo decisório que não domina.

O Estado do Rio de Janeiro, por oferecer condições para maior acumulação de capital, tem motivado inversões crescentes nas atividades em que tem vantagens comparativas, e de acordo com sua inserção no atual projeto nacional de desenvolvimento econômico, no qual é periférico em relação ao centro produtor mais avançado (São Paulo). Da mesma forma, também contribui para a integração internacional da economia brasileira de maneira subordinada (Araujo, 2000), usufruindo da maior demanda externa por recursos naturais e produtos primários, sendo esta apenas um dos vetores possíveis da atual configuração de forças com as quais o Brasil pode contar (Bielschowsky, 2013). Mediante "investimentos articulados de fora e para fora" (Cruz, 2013:18), seus efeitos no território contribuem para a exacerbação das desigualdades socioespaciais.

\subsection{Representatividade regional e desenvolvimento}

Avaliar o desempenho regional fluminense não implica desconsiderar a particularidade que a faz desigual. No Estado do Rio de Janeiro vive-se um estado de "macrocefalia metropolitana", como anteriormente mencionado, devido à elevada representatividade da Região Metropolitana relativamente às demais regiões. Esta característica se deve a que a atual capital do Estado foi a principal referência do país desde a sua descoberta, e não perdeu 
esta condição ao longo do Império e da chegada da República, tendo, portanto, recebido investimentos públicos e gozado de importância política até a transferência da capital para o planalto central em 1960.

Por ter recebido sucessivas e vultosas camadas de investimentos, públicos e privados, em 2010 a Região Metropolitana possuía a maior população residente entre as regiões (74\% do total), gerava o maior volume de riquezas (65,6\% do PIB a preço de mercado) e detinha o maior número de vínculos empregatícios $(77,1 \%)$, para mencionar algumas variáveis econômicas relevantes. Esta excessiva concentração, no entanto, vem acompanhada por um sem número de problemas de diversas naturezas (sociais, ambientais etc.) que não cabem considerar no momento, por fugir do propósito desta investigação. A condição da principal região em termos de desenvolvimento econômico, no entanto, preocupa mais por estar relativamente atrasada em termos de bem-estar, se comparada à sua representatividade.

Os resultados relativos aos níveis de desenvolvimento obtidos para as regiões em estudo tomaram os anos de 2000 e 2010 como referência, considerando que refletem os efeitos dos investimentos que vêm sendo feitos desde as décadas de 1980/1990 nas regiões que passaram a apresentar elevada atratividade. O que se pode perceber é que, a exemplo do que já se havia observado em esforço anterior (Medeiros Junior, 2013c, 2013d) a partir do Valor Adicionado Bruto (VAB), as regióes que receberam investimentos industriais apresentaram os maiores PIBs per capita, tais como a Norte Fluminense (R\$ 53.634), a da Costa Verde (R\$ 48.069) e a do Médio Paraíba (R\$ 34.203) (Tabela 2). Excetuando-se a região da Costa Verde, que tem no terciário o maior peso na geração do VAB por setores econômicos (Medeiros Junior, 2013d), as demais têm forte participação do setor industrial. Comparativamente à Região Metropolitana em 2010, a renda per capita das duas primeiras a superam em mais do que o dobro, relação que não existia em 2000.

\section{Tabela 2}

Produto Interno Bruto per capita, Produto Interno Bruto por trabalhador e utilização do trabalho segundo as Regiões de Governo e no Estado do Rio de Janeiro - 2000/2010

\begin{tabular}{|c|c|c|c|c|c|c|}
\hline \multirow[t]{2}{*}{ Estado e Regiões de Governo } & \multicolumn{2}{|c|}{ PIB per capita (R\$) } & \multicolumn{2}{|c|}{ PIB por trabalhador $(\mathrm{R} \$)$} & \multicolumn{2}{|c|}{ Utilização do trabalho (\%) } \\
\hline & 2000 & 2010 & 2000 & 2010 & 2000 & 2010 \\
\hline Estado do Rio de Janeiro & 9.642 & 25.455 & 25.103 & 56.789 & 38,7 & 44,8 \\
\hline Região Metropolitana & 9.772 & 23.255 & 25.664 & 52.138 & 38,3 & 44,6 \\
\hline Região Noroeste Fluminense & 5.198 & 12.210 & 12.566 & 27.214 & 41,6 & 44,9 \\
\hline Região Norte Fluminense & 12.869 & 53.634 & 33.650 & 123.516 & 38,6 & 43,4 \\
\hline Região Serrana & 6.942 & 19.228 & 16.146 & 39.459 & 43,2 & 48,7 \\
\hline Região das Baixadas Litorâneas & 7.904 & 26.579 & 21.913 & 60.062 & 38,8 & 44,3 \\
\hline Região do Médio Paraíba & 11.670 & 34.203 & 31.009 & 76.519 & 37,9 & 44,7 \\
\hline Região Centro-Sul Fluminense & 6.057 & 16.069 & 14.952 & 33.108 & 40,8 & 48,6 \\
\hline Região da Costa Verde & 8.180 & 48.069 & 22.265 & 105.204 & 37,4 & 45,6 \\
\hline
\end{tabular}

Fonte: IBGE, Censos Demográficos; Fundação CEPERJ.

Quando se leva em consideração o produto por trabalhador, proxy da produtividade do trabalho, a região Norte Fluminense mantém a liderança, mas a do Médio Paraíba perde a segunda colocação para a região da Costa Verde, que tem recebido investimentos e caracterizase por elevada participação do setor terciário (79,0\% do VAB em 2010), o que pode sugerir maior qualificação da força de trabalho. Tendo em vista, também, a hierarquia existente em 2000 quanto à produtividade do trabalho, na qual se observa que a Costa Verde apresentava resultados inferiores à média, percebe-se que houve incremento significativo, a ponto de em 2010 se aproximar ao dobro da média estadual. 
Já quanto ao outro componente do PIB per capita, a participação da população na atividade econômica regional se elevou entre 2000 e 2010 em todas as regióes, o que indica maior ocupação de fração dos residentes no processo produtivo regional. Dentre as regiões, as que demonstraram maior variação em pontos percentuais (p.p.) foram a da Costa Verde (+8,3 p.p.), a do Centro-Sul Fluminense (+7,8 p.p.) e a do Médio Paraíba (+6,8 p.p.). Cabe ressaltar que, das regiões mencionadas, apenas a da Costa Verde apresentou motivação migratória mais recente no último período intercensitário (2000-2010), bem como exibiu elevado crescimento populacional anual desde 1980/1991 e, a julgar pela melhoria relativa na produtividade do trabalho observada anteriormente, comparativamente às demais a região se beneficiou de maneira muito peculiar da combinação entre o acréscimo populacional e utilização da mão de obra. O mesmo não se poderia dizer da região Norte Fluminense, que, apesar de possuir o maior nível de desenvolvimento econômico e trabalhadores mais produtivos, tem a pior taxa de ocupação da população total.

\subsection{Desenvolvimento e estagnação da renda per capita}

Apesar de a decomposição utilizada neste trabalho demonstrar que a utilidade do trabalho influencia o comportamento do PIB per capita, é de conhecimento que este indicador evolui em grande parte devido à produtividade do trabalho, como os resultados na Tabela 2 indicam. Para melhor visualização desta relação, a Figura 1 apresenta os números-índices de cada uma das dimensões, tomando a média como referência. Pode-se notar que há correlação elevada e positiva entre os indicadores, bem como o nível de disparidade existente entre as regiões em termos de desenvolvimento. Não por acaso, as que se posicionam à direita e acima, mais desenvolvidas e possuidoras de maior produtividade do trabalho, são as que possuem setores que têm figurado no mapa dos investimentos.

Como se não bastasse o desnível do PIB per capita entre as regiões, sua evolução entre os anos 2000 e 2010 demonstra que esta situação tende a agravar-se (Tabela 3). Considerandose a variação da renda per capita no período, as regiões da Costa Verde (9,5\% ao ano), Norte Fluminense (5,8\% a.a.), das Baixadas Litorâneas (3,6\% a.a.) e do Médio Paraíba (2,2\% a.a.) apresentaram as maiores variações, sendo estas as quatro mais desenvolvidas segundo o indicador utilizado (Figura 1).

Figura 1

PIB per capita e produtividade regional em 2010

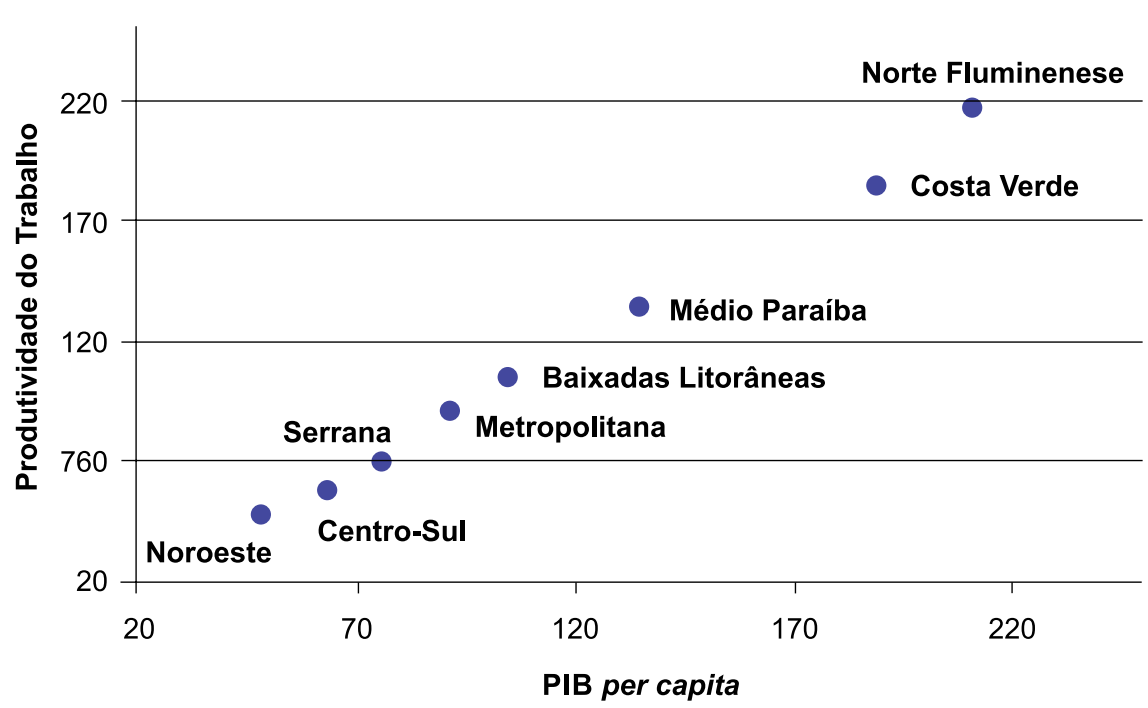


Para as mesmas regiões mais dinâmicas, a decomposição da variação do PIB per capita demonstra que nem todas basearam seu desenvolvimento nos mesmos requisitos, haja vista mostrarem comportamentos diferentes. Enquanto nas regiões da Costa Verde e do Norte Fluminense a produtividade do trabalho foi a principal responsável pelo crescimento com, respectivamente, $78 \%$ e $79 \%$ da variação da renda per capita, na das Baixadas Litorâneas a produtividade foi ligeiramente mais importante (53\%) para o crescimento, enquanto na do Médio Paraíba a maior contribuição foi devida ao aumento da utilização do trabalho (79\%). Vê-se, pois, que, para alcançar um maior desenvolvimento, cada região contou com uma combinação particular e de acordo com suas características, o que sugere não haver modelos de aplicação genéricos para chegar ao mesmo fim, exceto se as condições peculiares a cada espaço sejam consideradas. Enquanto a região da Costa Verde, especializada no setor terciário, apresentou resultados superiores às demais, que possuem maior participação industrial em sua estrutura econômica, dentre estas a região do Médio Paraíba baseou seu desenvolvimento na maior participação da população no processo produtivo, sendo, pois, socialmente mais inclusiva do que as demais regiões de característica semelhante.

Tabela 3

Variação real anual do Produto Interno Bruto per capita e decomposição da variação real anual segundo a produtividade do trabalho e a utilização do trabalho nas Regiões de Governo e no Estado do Rio de Janeiro - 2000/2010

\begin{tabular}{l|c|c|c}
\hline \multirow{2}{*}{ Estado e Regiões de Governo } & & \multicolumn{3}{|c}{ Variação real anual do PIB per capita (\%) } \\
\cline { 2 - 4 } & Total & \multicolumn{2}{|c}{ Decomposição da variação real anual } \\
\cline { 3 - 4 } Estado do Rio de Janeiro & 1,1 & $\mathbf{- 0 , 5}$ & Utilização do trabalho \\
Região Metropolitana & 0,1 & $-2,9$ & $\mathbf{1 , 6}$ \\
Região Noroeste Fluminense & $-0,1$ & $-0,5$ & 3,0 \\
Região Norte Fluminense & 5,8 & 4,6 & 0,4 \\
Região Serrana & 1,6 & 0,3 & 1,2 \\
Região das Baixadas Litorâneas & 3,6 & 1,9 & 1,3 \\
Região do Médio Paraíba & 2,2 & 0,5 & 1,7 \\
Região Centro-Sul Fluminense & 1,2 & $-0,6$ & 1,7 \\
Região da Costa Verde & 9,5 & 7,5 & 1,8 \\
\hline
\end{tabular}

Fonte: IBGE, Censos Demográficos; Fundação CEPERJ.

Um segundo grupo de regiões apresentou níveis inferiores de crescimento anual do PIB per capita, tais como a Serrana ( $+1,6 \%$ a.a.) e a do Centro-Sul Fluminense (+1,2\% a.a.). Estas, a exemplo da região industrial do Médio Paraíba, contaram com maior taxa de participação da população total, sendo que na Centro-Sul Fluminense houve queda da produtividade do trabalho (-0,6\% a.a.), que virá comprometer seu desenvolvimento na década em curso.

Por fim, e no extremo oposto das regiões dinâmicas, encontram-se aquelas cuja variação da renda per capita demonstra um estado de estagnação, como a Metropolitana ( $+0,1 \%$ a.a.) e a Noroeste Fluminense (-0,1\% a.a.). Nas duas regiões houve queda anual da produtividade do trabalho (-2,9\% a.a. e -0,5\% a.a., respectivamente), resultado que, apesar de não ser possível afirmar a partir das informações tratadas neste trabalho, pode sugerir emigração de força de trabalho no período intercensitário de 2000-2010 para as regiões mais dinâmicas, nas quais a recepção de migrantes teve motivação mais recente mediante processos urbano-urbano, ou rural-urbano, e de acordo com as condições particulares de desenvolvimento das regiões (Zelinsky, 1971). Em ambos os casos, portanto, a estagnação apresentada é particularmente grave. Na Região Metropolitana por ser a maior do Estado e que detém o maior contingente 
populacional, e na Noroeste Fluminense por ser a que apresentou maior especialização na atividade Agropecuária (Medeiros Junior, 2013d), cujo crescimento no período 2000-2010, de $0,6 \%$ a.a., foi muito inferior ao dos demais setores econômicos (2,3\% a.a. na Indústria e 2,7\% a.a. em Serviços) (FUNDAÇÃO CEPERJ, 2014).

\subsection{Desigualdade de renda e desenvolvimento social regional}

A partir da observação da evolução das regiões em termos da dinâmica de desenvolvimento e de seus componentes, conjugada com o nível de desigualdade de renda existente, buscou-se perceber se os frutos do aumento da renda beneficiaram a população.

No grupo das regiões mais desenvolvidas, o crescimento anual do PIB per capita da região Norte Fluminense teve na produtividade do trabalho a maior contribuição (79\%), mas a taxa de participação da população total foi a menor entre todas as regiões $(43,4 \%)$ e com elevada desigualdade de renda $(0,492)$; na região da Costa Verde, a segunda mais desenvolvida e que também contou com maior participação da produtividade do trabalho no crescimento da renda per capita (78\%), a utilização do trabalho é a maior do grupo $(45,6 \%)$ mas também é a região mais desigual $(0,510)$; na região do Médio Paraíba, terceira mais desenvolvida, a utilização do trabalho foi responsável pela maior contribuição ao aumento da renda per capita (79\%), mas a utilização do trabalho é ligeiramente inferior à da Costa Verde $(44,7 \%)$ e a desigualdade é a menor do grupo $(0,488)$; e a região das Baixadas Litorâneas, cuja influência do crescimento da produtividade foi quase idêntica à da utilização do trabalho (53\% a 47\%, respectivamente) para a evolução do PIB per capita, apresenta taxa de ocupação total da população de $44,3 \%$, pouco maior que a da Norte Fluminense, para um nível de desigualdade semelhante à da Costa Verde: 0,509. Entre as regiões deste grupo, na do Médio Paraíba, na qual a contribuição para o desenvolvimento no período em estudo se deu com maior participação da população empregada no processo produtivo, o índice de Gini foi menor.

Nas regiões do grupo intermediário em termos da dinâmica de desenvolvimento, a região Centro-Sul Fluminense possuía índice de Gini de 0,504, próximo ao do grupo das mais desenvolvidas, e também teve maior participação da utilização do trabalho no crescimento da renda per capita, enquanto a região Serrana apresentava o segundo menor Gini $(0,487)$ e também teve na maior participação da população no processo produtivo a maior influência no crescimento da renda per capita. Aparenta, portanto, que, em razão da quebra do padrão observado anteriormente, a região Centro-Sul Fluminense, que a exemplo da Noroeste Fluminense é especializada no setor primário, esteja caminhando na mesma direção e venha apresentar resultados semelhantes ao longo desta década.

Por fim, e considerando-se as regiões que apresentaram relativa estagnação do crescimento da renda per capita entre 2000 e 2010, a Metropolitana e a Noroeste Fluminense possuíam índices de Gini relativamente baixos (0,472 e 0,488, respectivamente), sendo menos desiguais, mas só não tiveram resultados piores quanto à queda da renda devido à influência do crescimento da utilização do trabalho, já que apresentaram queda de produtividade. Do exposto, portanto, excetuando-se situações específicas anteriormente mencionadas, os dados sugerem que maior utilização do trabalho como fonte para o crescimento da renda per capita retorna menor desigualdade de renda, na medida em que a inserção dos residentes no processo produtivo é maior. Em linha com esta leitura, e com base em indicadores relacionados à produção e reprodução da força de trabalho (Medeiros Junior, 2014b), as regiões fluminenses que receberam investimentos, e conforme os dados analisados tiveram 
maiores taxas de crescimento do PIB per capita, também apresentavam desenvolvimento social mais precário, o que demonstra que os ganhos decorrentes da acumulação de capital, se não revertidos em maior participação da população no processo produtivo, poderão ocasionar maior desigualdade.

Ainda quanto à desigualdade de renda domiciliar, seus níveis também se revelam em desagregações alternativas. Assim como se observa desigualdade de renda regionalmente, internamente a cada região há considerável disparidade se selecionadas as principais cidades quanto à renda domiciliar per capita (Tabela 4) relativamente à da sua região. Na região Metropolitana, por exemplo, os índices de Gini das cidades com as maiores rendas domiciliares per capita demonstram condições opostas: a cidade do Rio de Janeiro apresenta elevado Gini $(0,620)$ para uma renda média domiciliar que é o dobro da média da região Metropolitana, enquanto em Niterói a renda domiciliar se aproxima do triplo da média da região, mas com um Gini menor (0,590), o que sugere que na antiga capital do Estado a distribuição da renda é menos desigual do que na atual. O mesmo já não acontece na região Noroeste Fluminense, na qual a cidade de maior renda domiciliar per capita é a mais desigual: Bom Jesus do Itabapoana.

Tabela 4

Índice de Gini e renda domiciliar per capita segundo as Regiões de Governo e as principais cidades de cada Região no Estado do Rio de Janeiro - 2010

\begin{tabular}{|c|c|c|}
\hline Estado, Regiões de Governo e principais cidades & Índice de Gini & Renda domiciliar per capita (R\$) \\
\hline Estado do Rio de Janeiro (1) & 0,590 & $1.039,30$ \\
\hline Região Metropolitana & 0,472 & 718,60 \\
\hline Niterói & 0,590 & $2.000,29$ \\
\hline Rio de Janeiro & 0,620 & $1.492,63$ \\
\hline Região Noroeste Fluminense & 0,488 & 574,36 \\
\hline Bom Jesus do Itabapoana & 0,560 & 717,69 \\
\hline Itaperuna & 0,470 & 688,83 \\
\hline Região Norte Fluminense & 0,492 & 658,94 \\
\hline Macaé & 0,560 & 1103,42 \\
\hline Região Serrana & 0,487 & 630,18 \\
\hline Petrópolis & 0,550 & 922,49 \\
\hline Nova Friburgo & 0,510 & 894,75 \\
\hline Teresópolis & 0,560 & 859,79 \\
\hline Região das Baixadas Litorâneas & 0,509 & 734,73 \\
\hline Rio das Ostras & 0,530 & 1051,19 \\
\hline Região do Médio Paraíba & 0,488 & 690,10 \\
\hline Volta Redonda & 0,500 & 920,51 \\
\hline Resende & 0,520 & 915,21 \\
\hline Região Centro-Sul Fluminense & 0,504 & 648,32 \\
\hline Miguel Pereira & 0,550 & 801,63 \\
\hline Região da Costa Verde & 0,510 & 788,40 \\
\hline Mangaratiba & 0,510 & 832,15 \\
\hline
\end{tabular}

Fonte: IBGE, Censos Demográficos; PNUD.

(1) As informações para o Estado do Rio de Janeiro foram calculadas a partir do conjunto das Unidades da Federação.

A desigualdade, por seu turno, resulta de fatores históricos que determinaram o desenvolvimento de cada região, bem como de cada cidade dentro do contexto de sua região. Dependendo do nível geográfico de interesse para o qual os indicadores escolhidos nesta sessão forem tabulados (mesorregião, microrregião ou setor censitário, por exemplo), se apresentarão de forma semelhante, ou seja, de maneira desigual, haja vista ser a desigualdade 
inerente ao capitalismo. Isso sugere que no trato de questões territoriais não há receita pronta nem futuro pré-definido, uma vez que a condição social e econômica existente em cada território expressa o resultado no tempo de relações sociais definidas por sua trajetória, e o caminho em uma dada direção é particular, longe da pretensa homogeneidade que em geral habita o modo de pensar neoclássico.

\section{Considerações finais}

Dadas as condições mencionadas anteriormente, relativas aos efeitos da ação do capital no território, a desigualdade regional e socioespacial do desenvolvimento fluminense tende a se manter, ou agravar-se. Levantamentos recentes quanto à intenção de investimento ao longo dos anos 2010 (FIRJAN, 2009, 2012, 2014) indicam semelhante orientação regional e para a maioria dos setores de atividade escolhidos nas décadas anteriores, o que pode contribuir para a continuidade dos fluxos migratórios de força de trabalho para as regióes com maior dinamismo, em detrimento das que já apresentam relativa estagnação, desinteressantes para o capital e sem perspectiva de apoio do Estado para contrapor o desenvolvimento regional desigual em curso.

Estas observações tomam por referência que a superioridade das regiões com característica industrial tem por base setores com maior densidade de capital, resultando em maior capacidade de inovação, disseminação tecnológica e de produção (Rosendo e Britto, 2011), tais como os de extração e de refino de petróleo e gás, e o automobilístico, por exemplo, e os efeitos levarão à maior disparidade regional do desenvolvimento, bem como da ratificação da divisão inter-regional do trabalho em razão da mobilidade do capital industrial (Oliveira e Reichstul, 1973). Estas mesmas regiões, que no período intercensitário recente apresentaram elevado poder de atração, tenderão a mantê-lo, absorvendo força de trabalho que irá proporcionar aumentos do PIB per capita e, por conseguinte, da produtividade.

Assim, em razão das análises realizadas nesta investigação, os efeitos decorrentes do volume de investimentos na desigualdade socioespacial de oportunidades (e não só quanto à desigualdade de renda per capita) serão mais perversos que os já existentes, a não ser que o Estado implemente políticas públicas que venham contrapor a tendência em curso. Não se imagina que, ante as evidências de maior desigualdade de renda entre os anos 2000 e 2010, a fase atual da evolução dos diferenciais de renda inter-regional estejam se reduzindo como proposto por Williamson (1977), ou em processo de convergência segundo a teoria neoclássica do crescimento econômico, mas sim pareçam seguir o curso imaginado por Myrdal (1972) ao longo dos anos 2010, com resultados nefastos para a coesão social nas regiões menos desenvolvidas do Estado do Rio de Janeiro, bem como com o agravamento das condições de inserção produtiva da população trabalhadora nas regiões mais desenvolvidas.

\section{Referências bibliográficas}

ARAÚJO, Tânia Bacelar. Ensaios sobre o desenvolvimento brasileiro: heranças e urgências. Rio de Janeiro: REVAN / Fase, 2000.

BIELSCHOWSKY, R. Estratégia de desenvolvimento e as três frentes de expansão no Brasil: 
um desenho conceitual. Texto para discussão, IPEA, Brasília/Rio de Janeiro, n. 1828, abr. 2013. Disponível em: <www.ipea.gov.br>. Acesso em 21 maio 2014.

CRUZ, José Luis Vianna da. Os desafios da construção do desenvolvimento no Estado do Rio de Janeiro. Cadernos do Desenvolvimento Fluminense, Rio de Janeiro, n. 2, jul. 2013.

FERREIRA, P. C.; VELOSO, F. O desenvolvimento econômico brasileiro no pós-guerra. In: VELOSO, F. et al. Desenvolvimento econômico: uma perspectiva brasileira. Rio de Janeiro: Elsevier, 2013.

FIRJAN. Decisão Rio 2010-2012. Rio de Janeiro: FIRJAN, 2009.

. Decisão Rio 2012-2014. Rio de Janeiro: FIRJAN, 2012.

. Decisão Rio 2014-2016. Rio de Janeiro: FIRJAN, 2014.

FUNDAÇÃO CEPERJ. Anuário estatístico do Rio de Janeiro 2010. Rio de Janeiro, 2011. 1 CDROM.

. Estado do Rio de Janeiro: um breve balanço da década. Rio de Janeiro, [2012]. 26p.

. Anuário estatísco 2013 online. Rio de Janeiro, 2014. Disponível em: < http://www. ceperj.rj.gov.br/ceep/anuarios.html>. Acesso em 15 abr. 2014.

KALECKI, M. Teoria da dinâmica econômica: ensaio sobre as mudanças cíclicas e a longo prazo da economia capitalista. São Paulo: Nova Cultural, 1985.

KEYNES, J. M. A teoria geral do emprego, do juro e da moeda. São Paulo: Nova Cultural, 1988.

MASSEY, D. Spatial divisions of labor: social structures and the geography of production. New York: Routledge, 1995.

MEDEIROS JUNIOR, H. O papel das cidades e a realidade municipal fluminense: métricas e indicadores para planejamento. In: XV SEMANA IPPUR: Espaço e vida pública, território, imaginário, poder, 2009, Rio de Janeiro. SEMANA IPPUR, 15., 2009, Rio de Janeiro, Anais... UFRJ/IPPUR, 2009. 1 CD-ROM.

. Mudanças de estado do mercado de trabalho fluminense: diferenças regionais entre 2000 e 2010. In: ENCONTRO NACIONAL DE ESTUDOS POPULACIONAIS: transformações na população brasileira: complexidades, incertezas e perspectivas (18.: 2012a: Águas de Lindóia, SP). Anais eletrônicos... Disponível em: <http://www.abep.nepo.unicamp.br/xviii/ anais/site/index.php>.

. Dinâmica econômica e o mercado de trabalho fluminense entre 2000 e 2010. In: SEMINÁRIO DINÂMICA ECONÔMICA E DESENVOLVIMENTO REGIONAL, 1., 2012, Uberaba. Anais... Uberaba, UNIVERSIDADE FEDERAL DO TRIÂNGULO MINEIRO, 2012b. 1 CD-ROM.

. Desconcentração econômica e atratividade regional no estado do Rio de Janeiro entre 2000 e 2010. Cadernos do Desenvolvimento Fluminense, Rio de Janeiro, n. 1, fev. 2013a. Disponível em: <http://www.e-publicacoes.uerj.br/index.php/cdf>.

. Dinâmica populacional e econômica regional, e o mercado de trabalho fluminense entre 2000 e 2010. In: ENCONTRO DA ANPUR: desenvolvimento, planejamento e governança, 15., 2013, Recife. Anais... Recife, ANPUR, 2013b. 1 CD-ROM 
. Mudanças na divisão inter-regional do trabalho fluminense: desenvolvimento desigual da renda interna entre 2000 e 2010. In: SEMANA IPPUR: planejamento, desigualdade e justiça social: desafios para as cidades e regiões, 19., 2013, Rio de Janeiro, Anais... Rio de Janeiro, UFRJ/IPPUR, 2013c.

. Divisão territorial do trabalho e produtividade regional fluminense nos anos 2000. Cadernos do Desenvolvimento Fluminense, Rio de Janeiro, n. 3, nov. 2013d. Disponível em: <http://www.e-publicacoes.uerj.br/index.php/cdf>.

- Mudanças regionais e a dimensão social do desenvolvimento fluminense nos anos de 2000 e 2010. In: SEMINÁRIO DE DESENVOLVIMENTO REGIONAL, ESTADO E SOCIEDADE, 2., 2014, Campina Grande. Anais GT6 - Dinâmicas regionais e socioespaciais contemporâneas. Campina Grande, UEPB, 2014b.

MEDEIROS JUNIOR, H.; GRAND JUNIOR, J. Distribuição dos empregos formais na cidade do Rio de Janeiro: uma análise exploratória. In: SEMANA IPPUR: um território em disputa, 16., 2010, Rio de Janeiro, Anais... Rio de Janeiro, UFRJ/IPPUR, 2010. Disponível em: < http:// www.ippur.ufrj.br/download/semana_pur_2010/completos/helcio_joao.pdf > .

. Geografia econômica regional fluminense nos anos 00: aumento de riqueza, expectativa de pobreza. In: ENCONTRO DA ANPUR: quem planeja o território? Atores, arenas e estratégias, 14., 2011, Rio de Janeiro. Anais... Rio de Janeiro, ANPUR, 2011a. 1 CD-ROM

. Distribuição dos empregos formais na cidade do Rio de Janeiro: uma análise espacial. In: ENCONTRO DA ANPUR: quem planeja o território? Atores, arenas e estratégias, 14., 2011, Rio de Janeiro. Anais... Rio de Janeiro, ANPUR, 2011b. 1 CD-ROM

MEDEIROS JUNIOR, H.; SOUZA, Laumar N. Mudanças de estado e comportamento da oferta e ocupação no mercado de trabalho da RMS. Conjuntura \& Planejamento, Salvador, n. 182, p. 28-41, jan.-mar. 2014a. Disponível em: <http://www.sei.ba.gov.br>.

. O desempenho recente do mercado de trabalho na Região Metropolitana de Salvador. In: PESSOTI, G. C.; WANDERLEY, L. A. (Orgs.). Reflexões de economistas baianos 2014. Salvador: Corecon-BA, 2014c.

. Mudanças de estado e comportamento da oferta e ocupação no mercado de trabalho da Região Metropolitana de Salvador. In: ENCONTRO DE ECONOMIA BAIANA, 10., 2014, Salvador. Anais... Salvador, SEI-BA/Desenbahia, 2014d. 1 CD-ROM. Disponível em: <http:// www.eeb.sei.ba.gov.br>.

MYRDAL, Gunnar. Teoria econômica e regiões subdesenvolvidas. 3. ed. Rio de Janeiro: Saga, 1972.

NATAL, Jorge L.A. O Estado do Rio de Janeiro pós-1995: dinâmica econômica, rede urbana e questão social. Rio de Janeiro: Pubblicati, 2005.

OLIVEIRA, F.J.G. Reestruturação produtiva: território e poder no Estado do Rio de Janeiro. Rio de Janeiro: Garamond, 2008.

OLIVEIRA, Francisco; REICHSTUL, Henri-Philippe. As mudanças na divisão inter-regional do trabalho no Brasil. Estudos CEBRAP, 4, pp. 131-168, 1973.

PACHECO, C. A. Fragmentação da nação. Campinas: Institudo de Economia/UNICAMP, 1998. 291p. 
PIQUET, R. P. S. Reestruturação do espaço regional e urbano no Brasil: o poder do Estado e dos grandes investimentos. Rio de Janeiro: UFRJ/IPPUR, 1993.

RESENDE, G.M.; MAGALHÃES, J.C.R. Disparidades do PIB per capita no Brasil. IPEA, Texto para Discussão, n. 1833, maio 2013.

ROSENDO, R. C.; BRITTO, J. Evolução da densidade industrial do Estado do Rio de Janeiro: análise comparativa com os estados do sudeste brasileiro-2000/2005. In: ENCONTRO NACIONAL DE ECONOMIA, 39, 2011, Foz do Iguaçu. Anais... Foz do Iguaçu, ANPEC, 2011. Disponível em: <www.anpec.org.br>.

SANCHEZ, Eramis Bueno. Población y desarrollo: enfoques alternativos de los estudios de poblacion. Ciudad de la Habana: Cedeiii/Universidad de la habana, 1994.

SILVA, R. D. Rio de Janeiro, crescimento, transformações e sua importância para a economia nacional (1930-2000). Dissertação (mestrado), Campinas, UNICAMP, 2004.

. Indústria e desenvolvimento regional no Rio de Janeiro (1990-2008). Rio de Janeiro: Editora FGV, 2012.

SMITH, Neil. Desenvolvimento desigual: natureza, capital e a produção do espaço. Rio de Janeiro: Bertrand Brasil, 1988. 250p.

SOUZA, Nali J. Desenvolvimento econômico. 5. ed. São Paulo: Atlas, 2007.

TROTSKY, L. A história da revolução russa. 2. ed. Rio de Janeiro: Paz e Terra, 1977. Disponível em: <http://www.marxists.org/portugues/trotsky/1930/historia/cap01.htm>. Acesso em 17 fev. 2012.

WILLIAMSON, J. G. Desigualdade regional e o processo de desenvolvimento nacional: descrição de padrões. In: SCHWARTZMAN, J. (Org.). Economia Regional: textos escolhidos. Belo Horizonte: Cedeplar, 1977.

ZELINSKY, W. The hypothesis of the mobility transition. The Geographical Review, vol. 61, n. 2, pp. 219-249, 1971. 